\title{
BMJ Open Agreement on the use of sensory screening techniques by nurses for older adults with cognitive impairment in long-term care: a mixed-methods consensus approach
}

Walter Wittich, ${ }^{\oplus 1,2}$ Jonathan Jarry, ${ }^{1,2}$ Fiona Höbler, ${ }^{3,4}$ Katherine S McGilton ${ }^{3,5}$

To cite: Wittich W, Jarry J, Höbler F, et al. Agreement on the use of sensory screening techniques by nurses for older adults with cognitive impairment in long-term care: a mixed-methods consensus approach. BMJ Open 2019;9:e027803. doi:10.1136/ bmjopen-2018-027803

- Prepublication history for this paper is available online. To view these files please visit the journal online (http://dx.doi org/10.1136/bmjopen-2017016527).

Received 08 November 2018 Revised 24 April 2019 Accepted 19 August 2019
Check for updates

(C) Author(s) (or their employer(s)) 2019. Re-use permitted under CC BY-NC. No commercial re-use. See rights and permissions. Published by BMJ.

For numbered affiliations see end of article.

Correspondence to Dr Walter Wittich; walter.wittich@umontreal.ca

\section{ABSTRACT}

Objective Based on two scoping reviews and two environmental scans, this study aimed at reaching consensus on the most suitable sensory screening tools for use by nurses working in long-term care homes, for the purpose of developing and validating a toolkit.

Setting A mixed-methods consensus study was conducted through two rounds of virtual electronic suitability rankings, followed by one online discussion group to resolve remaining disagreements.

Participants A 12-member convenience panel of specialists from three countries with expertise in sensory and cognitive ageing provided the ranking data, of whom four participated in the online discussion.

Outcome measures As part of a larger mixed-methods project, the consensus was used to rank 22 vision and 20 hearing screening tests for suitability, based on 10 categories from the Quebec User Evaluation of Satisfaction with Assistive Technology questionnaire. Panellists were asked to score each test by category, and their responses were converted to z-scores, pooled and ranked. Outliers in assessment distribution were then returned to the individual team members to adjust scoring towards consensus.

Results In order of ranking, the top 4 vision screening tests were hand motion, counting fingers, confrontation visual fields and the HOT-V chart, whereas the top 4 hearing screening tests were the Hearing Handicap Inventory for the Elderly, the Whisper Test, the Measure of Severity of Hearing Loss and the Hyperacusis Questionnaire, respectively.

Conclusions The final selection of vision screening tests relied on observable visual behaviours, such as visibility of tasks within the central or peripheral visual field, whereas three of the four hearing tests relied on subjective report. Next, feasibility will be tested by nurses using these tools in a long-term care setting with persons with various levels of cognitive impairment.

Research into sensory and cognitive ageing has pointed towards the association between sensory and cognitive health at midlife, ${ }^{1}$ whereby poorer sensory abilities in vision, hearing and olfaction are already associated
Strengths and limitations of this study

- This study brings together evidence and expertise in sensory assessment and cognitive ageing that were gathered across two previous scoping reviews and two environmental scans, from the literature as well as from clinical practice.

- The resulting consensus on sensory screening techniques in the long-term care environment builds the foundation for the development of a new screening tool to guide nurses in their efforts to identify vision and hearing loss in residents under their care.

- The variability in cognitive abilities of long-term care residents poses a challenge for screening techniques, and the flexibility required for testing often opposes validated test standards.

- To develop an effective screening tool for practice, there is a need for a better understanding of the links between sensory and cognitive abilities in older adults with dementia.

with reduced performance on cognitive tests. Similar findings have been reported in older adults, and sensory decline has been proposed as a possible early indicator for the development of dementia of the Alzheimer's type. ${ }^{2}$ These and similar studies have explored the links among visual, hearing and cognitive functions, with the goal of better understanding whether these symptoms may be signs of an underlying common cause, such a frailty, ${ }^{3}{ }^{4}$ or whether sensory decline may lead to cognitive impairment, or the other way around. ${ }^{5-10}$ In either case, impaired cognitive ability can seriously interfere with the capacity to detect potentially treatable sensory impairments. ${ }^{11}$ However, currently validated sensory screening tools that can be applied across a range of cognitive abilities are not available. Since sensory impairment jeopardises the administration and reliability of cognitive screening and assessment tools, 
there is a clear need to improve the ability to properly assess vision and hearing in older adults with dementia. This is of specific urgency among those living in longterm care homes (LTCHs), where the coexistence of vision and hearing impairments has been reported to be disproportionately high, ${ }^{12}$ especially with dementia of the Alzheimer's type being the most prevalent comorbidity in this population. ${ }^{13}$ Previous data have indicated that around $70 \%$ of older adults with dementia in LTCHs have some sensory deficits. ${ }^{14}$ Therefore, screening techniques for sensory impairments that are robust in the presence of cognitive impairment are needed by front-line health professionals (such as nurses) working in LTCHs. ${ }^{15} 16$

Nurses employed in LTCHs have further pointed at the importance of detecting and potentially remediating or rehabilitating sensory impairments in this population. The contributing influences of sensory and cognitive impairment on older adults' functioning are currently difficult for them to differentiate or to identify by use of standardised tests. ${ }^{16}$ The underlying assumption is that their LTCH residents can hear and see each test, its instructions, as well as the person administering it. However, given their prevalence, vision and hearing impairments can interfere with communication, ${ }^{17}$ as well as with the audibility ${ }^{18}$ and visibility ${ }^{19}$ of screening and testing materials and instructions. ${ }^{20}$ Therefore, screening for cognitive impairment in older adults with any level of vision and/or hearing impairment is likely to be somewhat unreliable if the sensory impairments are not considered during the administration of such tests. Even when such accommodations are made, the reliability and validity of the results may be jeopardised as the testing demands and conditions may no longer be optimal or comparable with the original standards. Therefore, the urgent requirement for reliable sensory screening tools that can be administered by front-line healthcare workers, such as nurses, becomes clear. This allows them to refer and allocate services accordingly, and thereby improve their residents' capacity to perform to the best of their actual abilities should their cognition be assessed, while also enhancing their patients' care, quality of life and independence.

In order to improve the ability of nurses working in LTCHs to detect sensory deficits in residents under their care, our team laid out a multistudy protocol with the goal of developing and validating a sensory screening toolkit. ${ }^{21}$ The first step was to conduct two scoping reviews with the aim of identifying screening tests for vision impairment ${ }^{22}$ and hearing loss (W. Wittich et al, in preparation), published in peer-reviewed literature, that have been used in the past with older adults who have cognitive impairment. The results presented by Campos and colleagues ${ }^{22}$ identified a combined total of 19 vision screening tests that were judged suitable for use by nurses working in LTCHs, and provide detailed information on their validity, reliability, sensitivity, specificity and sensibility. The majority of these tests were chart-based (eg, black letters on a white background) to be used near $(\mathrm{eg}, 40 \mathrm{~cm})$ or at a distance $(\mathrm{eg}, 6 \mathrm{~m}$ or across the room). Other tests focused on examination of ocular anatomy (eg, pupil reflex), visual field or self-report questionnaires of visual function. The hearing-related studies presented by Wittich and colleagues (in preparation) resulted in a list of 20 potentially suitable tests to detect changes in various aspects of hearing. The majority were questionnaire-based, to be administered verbally either to the individual with the impairment, for example, the Hearing Handicap Inventory for the Elderly, ${ }^{23}$ or to a member of their care team, for example, the staff version of the Nursing Home Hearing Handicap Index. ${ }^{24}$ Additional measures included aspects of anatomy, such as an otoscopic exam of the ear canal and wax build-up, as well as access to medical chart information.

In addition to the scoping review results, our team consulted with 20 nurses currently working in LTCHs to elucidate which approaches are currently in use for the identification of sensory loss in residents under their care, and which recommendations they could give to facilitate this process. ${ }^{16}$ Their recommendations highlighted the current absence of tools and training for sensory screening suitable for them and their residents, and confirmed the need for more appropriate methods of evaluation. In addition, respondents emphasised the importance of communication techniques with LTCH residents when screening, and the need for additional education of nurses and front-line staff about age-related sensory impairment, with the potential for improving the quality of life for their residents by leveraging and enhancing their sensory capacities. Finally, we consulted specialists in vision and hearing healthcare with specific professional experience in the sensory assessment of older adults with dementia. ${ }^{25}$ These specialists recommended an additional three testing tools that did not emerge in the scoping review, ${ }^{22}$ as well as more general approaches and adaptations to already existing validated and standardised tests. These included optimal management and additional allotment of time during the testing process, as well as a more flexible approach to the interpretation of what is considered a valid test response based on their clinical experience.

As the next logical step in our efforts to build and validate a sensory screening toolkit for nurses working with older adults living in LTCHs with various levels of dementia, the present study pooled the information gathered during our two scoping reviews (of vision and hearing tests) and two environmental scans (with nurses and sensory specialists). We then used a mixed-methods consensus process, presented here, in order to distil the most appropriate methods of screening for vision and hearing loss to be included in the final development, evaluation and validation of a sensory screening toolkit for older adults with dementia. 


\section{METHODS}

\section{Patient and public involvement}

The research question addressed in this study was developed in consultation with healthcare professionals who serve older adults living with dementia in long-term care, ${ }^{16}$ as well as with information drawn from a review of the existing research literature ${ }^{22}$ that included patient participants. However, this study did not directly rely on the involvement of patients or the public.

\section{Consensus method}

Given the time demands on specialised clinicians and researchers, we opted to use a mixed qualitative and quantitative methodology that would allow us to minimise the amount of time required for our experts to be able to participate, while maximising the richness and accuracy of the data obtained. Therefore, the first two rounds of our consensus approach (described below) used usability criteria previously established in the context of assistive device utilisation, ${ }^{26}$ but here applied to the usability of assessment technology and strategies, whereby our participants quantitatively judged the suitability of potential tests. Given the time involved in this task, this approach allowed participants to complete rounds 1 and 2 at a time of their choosing, in one or multiple sessions. Drawing from the Delphi methodology, ${ }^{27}$ we then recruited a subset of experts to participate in an online live panel discussion, in order to discuss the quantitative rankings, and resolve any remaining disagreements. In order to facilitate the comparison and ranking of the materials that were collected during the previous phases of this project, we were inspired by a reactive Delphi method approach, ${ }^{28}$ whereby panel members simply responded (reacted) to the information provided instead of generating their own list of items and suggestions. The consulted specialists are able to consider the question and materials presented to them individually, anonymously, and rely only on their own expertise, without being drawn into the dynamics of potential group debate or being influenced by dominating opinion leaders. ${ }^{29}$

\section{Consensus panel selection}

Given the reports of nurses working in long-term care, the majority of whom indicated that they considered themselves poorly trained or educated on sensory screening tools and techniques, ${ }^{16}$ the present study focused on recruiting and consulting experts with experience in sensory assessment, measurement and screening in the geriatric population. A panel of 12 experts in the fields of sensory and cognitive ageing with specific interest in multimorbidity were recruited through convenience sampling and networking of the investigative team members and collaborators (see table 1 for panellists' characteristics). The panel included members of and contributors to preceding studies, ${ }^{21}{ }^{22}$ along with experts who participated in one of the environmental scans ${ }^{25}$ and new members who were based further afield. The panel size of $\mathrm{n}=12$ falls within a previously established range of group
Table 1 Characteristics of expert panellists

\begin{tabular}{|c|c|c|}
\hline Type of expert & $\begin{array}{l}\text { Rounds } 1 \text { and } \\
2(n=12)\end{array}$ & $\begin{array}{l}\text { Round } 3 \\
(n=4)\end{array}$ \\
\hline Optometrist & $3(25 \%)$ & $2(50 \%)$ \\
\hline Audiologist & $3(25 \%)$ & $2(50 \%)$ \\
\hline Otolaryngologist & $1(8 \%)$ & \\
\hline Neuropsychologist & $2(16 \%)$ & \\
\hline Sensory ageing researcher & $2(16 \%)$ & \\
\hline $\begin{array}{l}\text { Deafblind rehabilitation } \\
\text { specialist }\end{array}$ & $1(8 \%)$ & \\
\hline \multicolumn{3}{|l|}{ Country/Province of employment } \\
\hline Canada & $10(83 \%)$ & $4(100 \%)$ \\
\hline Quebec & $2(16 \%)$ & $1(25 \%)$ \\
\hline Ontario & $7(58 \%)$ & $3(75 \%)$ \\
\hline British Columbia & $1(8 \%)$ & \\
\hline Australia & $1(8 \%)$ & \\
\hline UK & $1(8 \%)$ & \\
\hline \multicolumn{3}{|l|}{ Gender } \\
\hline Female & $9(75 \%)$ & $4(100 \%)$ \\
\hline \multicolumn{3}{|l|}{ Education } \\
\hline $\mathrm{PhD}$ & $8(67 \%)$ & $3(75 \%)$ \\
\hline Master's & $4(33 \%)$ & $1(25 \%)$ \\
\hline
\end{tabular}

sizes that allow for sufficient validity and reliability. ${ }^{30} 31$ The panel consisted of three optometrists, three audiologists, one otolaryngologist, two neuropsychologists, one deafblind rehabilitation specialist and two researchers specialising in sensory and cognitive ageing with specific experience working with persons with dementia, and all with a minimum of 5 years of professional experience in their respective fields.

\section{Test selection}

As part of the larger project, the earlier studies reviewed above $\left({ }^{1622} 25\right.$, W. Wittich et al., in preparation) provided the research team with a list of potentially useful sensory screening tests that have previously been used with older adults who had dementia or approximate levels of cognitive impairment. The resulting list of 22 vision and 20 hearing tools is the focus of the consensus study.

\section{Preparation of the evaluation material}

A one-page summary of each tool was assembled and included a picture of the tool as well as information pertaining to the following categories: area of assessment (vision or hearing), category of test (anatomy/physiology, behavioural, self-report, other-report), name of test, ability/function measured, approximate price (in $\$ C A D$ ), description, assessment data/results (the kind provided by the test), level and type of training/qualification required for administration as well as for interpretation, and the source/reference of the above information. This summary was provided because not all panel members would be 
sufficiently familiar with all tests or may not have used all of them themselves, at a level that they would be comfortable judging them. Panel members did have the option of requesting additional information or to opt out of rating individual tests, if they did not feel qualified to provide a score. These summaries were then transferred to an Excel workbook containing an evaluation grid for each tool. The coauthors then pilot-tested the workbook on two of the measures themselves in order to estimate the time required to complete the assignment and to make sure the instructions and process were clear. After final adjustments, the expert panellists received the complete workbook through an online file-sharing platform, DropCanvas (http://www. dropcanvas.com), along with an email containing instructions sent to all panellists, who were then given 3 weeks to complete the initial rating. They were asked to score each tool, specifically considering the context of nurses administering these measures in LTCHs with residents who had cognitive impairment, on a scale from 1 to 10 according to positive and negative characteristics adapted from the Quebec User Evaluation of Satisfaction with Assistive Technology questionnaire's evaluation categories. ${ }^{26}$ The five positive characteristics involved physical convenience, durability, ease of readiness, ease of operation and effectiveness (where 10 represented an ideal score, eg, optimal physical convenience), while the five negative characteristics were training needed, invasiveness, maintenance, cost and time (where 10 represented an ideal score, such as the lowest possible cost). Along with these individual scores, panellists were invited to provide a written justification, especially in the case of extreme scores, as well as overall qualitative feedback on the screening tool. Panellists were finally asked to contribute any sensory screening measure that was not included on the list, so that these may be considered and added to round 2 of the process.

\section{Scoring and round 1}

The raw scores out of 100 were collated for each tool and each panellist, and then converted to z-scores by subtracting the raw score from the panellist's mean score for all evaluated tools and dividing the result by the panellist's SD for all evaluated tools. When an evaluating panellist did not provide a score for a particular characteristic of a tool (mainly because they reported not being familiar enough with it), their partial score was converted to a score out of 100 before the transformation to a z-score. The 12 z-scores for each tool were then plotted in JASP (JASP Team, Amsterdam, The Netherlands) using box plots in order to identify outliers $(> \pm 3.0 \mathrm{SD})$. When an outlying score was generated by a panellist whose domain of expertise was different from the one in which the tool would be used (eg, a hearing specialist evaluating an eye chart), the outlier was dismissed. For all other cases, a special report was sent to the evaluator for the purpose of re-evaluation during round 2 .

\section{Round 2}

None of the panel members suggested additional tools to be included in round 2. Only the panellists whose z-scores for a given tool were marked as an outlier and whose area of expertise included the tool in question were approached for round 2. This choice was made to reduce participation burden. They received an updated Excel spreadsheet that reproduced the information on the tool they had accessed during round 1 , along with their original outlying score; the overall qualitative comments left by the other panellists for this tool; their own qualitative comments which they submitted during round 1 ; and for each of the 10 characteristics of the tool, the mean score for all panellists who rated it, its SD and any justification submitted by other panellists for their score. They were then asked to either revise their score, considering the placement of their standardised score when compared with the consensus panel mean (as a way of comparing themselves with the current group consensus), or to preserve their original score, but to justify this in more detail. The outliers from round 1 were then replaced in the analysis with the updated scores, and the data were restandardised, recalculated and plotted again to identify potential round 2 outliers.

\section{Round 3: panel discussion and consensus}

In order to establish final consensus and to resolve any remaining outlier scores, a subset of four panel members (two hearing experts, two vision experts) together with the two team leaders were invited to a $90 \mathrm{~min}$ virtual online meeting in order to discuss and resolve any remaining outliers, to confirm consensus on the final test rankings and to recommend which tests from this ranking will be included in the validation of the sensory screening toolkit.

\section{RESULTS}

\section{Round 1}

Quantitatively, three panellists, two of whom were hearing specialists and one with experience in deafblind rehabilitation, scored three hearing tests as outliers. Four panel members, three of whom had experience in vision care and one with experience in deafblindness, scored four vision tests as outliers. Qualitatively, several panellists remarked that they foresaw difficulties in the scoring and agreement process, based on the need to potentially adjust the administration of some of the tests, depending on the severity level of dementia in the individuals being tested. Such adjustments would need to be considered in the ranking, and their comments were preserved to inform the discussions in round 3.

\section{Round 2}

After rescoring the outliers from round 1, one hearing test (pure tone audiometry) remained as having an extreme score (from the deafblind rehabilitation professional), and three vision tests (Feinbloom chart, Ishihara plates and Rosenbaum chart) remained with extreme scores from one vision and one deafblind rehabilitation professional. Their qualitative comments were forwarded to be part of the consensus discussions 
Table 2 Pearson's correlation coefficients for the 11 experts who provided scores across all vision tests

\begin{tabular}{|c|c|c|c|c|c|c|c|c|c|c|c|}
\hline & 1 & 2 & 3 & 4 & 5 & 6 & 7 & 9 & 10 & 11 & 12 \\
\hline 1 & - & & & & & & & & & & \\
\hline 2 & $0.791^{\star \star \star}$ & - & & & & & & & & & \\
\hline 4 & $0.946^{\star \star \star}$ & $0.876^{\star \star \star}$ & $0.760^{\star \star \star}$ & - & & & & & & & \\
\hline 5 & $0.635^{\star \star \star}$ & $0.882^{\star \star \star}$ & $0.792^{\star \star *}$ & $0.674^{\star \star}$ & - & & & & & & \\
\hline 7 & $0.789^{\star \star \star}$ & $0.746^{\star \star \star}$ & $0.769^{\star \star \star}$ & $0.833^{\star \star \star}$ & $0.644^{\star *}$ & $0.579^{\star \star}$ & - & & & & \\
\hline 9 & $0.933^{\star \star \star}$ & $0.798^{\star \star \star}$ & $0.750^{\star \star \star}$ & $0.975^{\star \star \star}$ & $0.633^{\star \star}$ & $0.740^{\star \star \star}$ & $0.808^{\star \star \star}$ & - & & & \\
\hline 10 & $0.861^{\star * *}$ & $0.755^{\star \star *}$ & $0.655^{\star \star *}$ & $0.922^{\star * *}$ & $0.707^{\star * *}$ & $0.675^{\star \star *}$ & $0.757^{\star * \star}$ & $0.896^{\star * *}$ & - & & \\
\hline 11 & $0.662^{\star \star}$ & $0.758^{\star \star \star}$ & $0.745^{\star \star \star}$ & $0.648^{\star \star}$ & $0.753^{\star \star \star}$ & $0.532^{\star \star}$ & $0.575^{\star \star}$ & $0.588^{\star \star}$ & $0.618^{\star \star}$ & - & \\
\hline 12 & $0.684^{\star \star \star}$ & $0.720^{\star \star \star}$ & $0.752^{\star \star \star}$ & $0.667^{\star \star}$ & $0.591^{\star *}$ & $0.395^{\star}$ & $0.592^{* *}$ & $0.606^{\star *}$ & $0.441^{*}$ & $0.641^{* \star *}$ & \\
\hline
\end{tabular}

All tests are one-tailed, for positive correlation.

${ }^{\star} \mathrm{P}<0.05,{ }^{* \star} \mathrm{p}<0.01,{ }^{\star \star *} \mathrm{p}<0.001$, one-tailed.

in round 3. We calculated Krippendorff's alpha, ${ }^{32}$ with 95\% CI based on 1000 bootstrap samples with replacement, as a measure of intercoder agreement, as it is suitable for multiple coders scoring on continuous outcomes. Please note that we opted for Krippendorff's alpha instead of intraclass correlation coefficients because of missing values for some of the measures by some experts, which strongly affect the calculation of intraclass correlation coefficients, but less so of alpha. For the 22 measures of vision, the data from 11 experts who provided scores generated an alpha of 0.68 (95\% CI 0.63 to 0.71 ), whereas for 20 measures of hearing the data from 10 experts who provided scores resulted in an alpha of 0.75 (95\% CI 0.64 to 0.82 ). Pearson's correlation coefficients for the scores of all panel members after round 2, separated by vision and hearing tests, are presented in tables 2 and 3, respectively, ranging from $r=0.37$ to $r=0.94$ for vision, and from $r=0.54$ to $r=0.95$ for hearing scores. The results of the ranking of all vision and hearing screening tools for rounds 1 and 2 are presented in tables 4 and 5, respectively.

\section{Round 3}

The goal of the online consensus meeting was to discuss and resolve any discrepancies that emerged during rounds 1 and 2, finalise the rankings of both vision and hearing tests, as well as generate agreement of recommendations for the tools to be included in the subsequent validation process. The four experts and two team leaders briefly discussed the overall ranking results to determine any unexpected outcomes. Having determined good face value of the results, they then focused on the five items scored most highly for each sensory domain, and discussed their perspectives on the feasibility of including each of these tests in the final validation phase. In order of ranking, the top four vision screening tests were hand motion, counting fingers, confrontation visual fields and the HOT-V chart, whereas

Table 3 Pearson's correlation coefficients for the 10 experts who provided scores across all hearing tests

\begin{tabular}{|c|c|c|c|c|c|c|c|c|c|c|}
\hline & 1 & 2 & 3 & 4 & 5 & 6 & 7 & 8 & 9 & 12 \\
\hline 1 & - & & & & & & & & & \\
\hline 2 & $0.956^{\star \star \star}$ & - & & & & & & & & \\
\hline 4 & $0.921^{\star \star *}$ & $0.823^{\star \star \star}$ & $0.788^{\star \star \star}$ & - & & & & & & \\
\hline 5 & $0.791^{\star \star \star}$ & $0.828^{\star \star \star}$ & $0.821^{\star \star \star}$ & $0.767^{\star \star}$ & - & & & & & \\
\hline 7 & $0.887^{\star \star \star}$ & $0.883^{\star \star \star}$ & $0.908^{\star \star *}$ & $0.592^{*}$ & $0.781^{\star \star \star}$ & $0.677^{\star \star \star}$ & - & & & \\
\hline 8 & $0.892^{\star \star \star}$ & $0.845^{\star \star \star}$ & $0.766^{\star \star \star}$ & $0.837^{\star \star \star}$ & $0.614^{\star \star}$ & $0.916^{\star \star \star}$ & $0.777^{\star \star \star}$ & - & & \\
\hline 9 & $0.846^{\star \star \star}$ & $0.860^{\star \star \star}$ & $0.872^{\star \star *}$ & $0.830^{\star \star \star}$ & $0.788^{\star \star *}$ & $0.751^{\star \star \star}$ & $0.770^{\star \star \star}$ & $0.698^{\star \star}$ & - & \\
\hline 12 & $0.878^{\star \star \star}$ & $0.832^{\star \star *}$ & $0.846^{\star \star \star}$ & $0.884^{\star \star \star}$ & $0.765^{\star \star \star}$ & $0.765^{\star \star \star}$ & $0.811^{\star \star \star}$ & $0.846^{\star \star \star}$ & $0.874^{\star \star \star}$ & - \\
\hline
\end{tabular}

All tests are one-tailed, for positive correlation.

${ }^{*} \mathrm{P}<0.05,{ }^{* *} \mathrm{p}<0.01,{ }^{* *} \mathrm{p}<0.001$, one-tailed. 
Table 4 The z-scores for vision tests with ranking at rounds 1 and 2

\begin{tabular}{|c|c|c|c|c|}
\hline \multirow[b]{2}{*}{ Tool } & \multicolumn{4}{|c|}{ Mean z-scores and rankings } \\
\hline & Round 1 & Rank & Round 2 & Rank \\
\hline Hand motion & 1.022 & 1 & 1.050 & 1 \\
\hline Counting fingers & 0.953 & 2 & 1.004 & 2 \\
\hline Confrontation visual fields & 0.803 & 3 & 0.832 & 3 \\
\hline HOT-V chart ${ }^{41}$ & 0.589 & 6 & 0.622 & 4 \\
\hline Acuity cards (letters) & 0.595 & 4 & 0.599 & 5 \\
\hline $\begin{array}{l}\text { Lighthouse Near Visual Acuity } \\
\text { Test } \\
\text { (Modified Early Treatment for } \\
\text { Diabetic Retinopathy Study/ } \\
\text { ETDRS chart) }\end{array}$ & 0.591 & 5 & 0.594 & 6 \\
\hline Snellen eye chart ${ }^{42}$ & 0.553 & 7 & 0.569 & 7 \\
\hline Red cap test & 0.410 & 10 & 0.495 & 8 \\
\hline Landolt 'C' chart & 0.427 & 8 & 0.419 & 9 \\
\hline $\begin{array}{l}\text { Rosenbaum Pocket Vision } \\
\text { Screener }\end{array}$ & 0.422 & 9 & 0.403 & 10 \\
\hline $\begin{array}{l}\text { Intake Questionnaire and } \\
\text { Functional Scales }\end{array}$ & 0.308 & 13 & 0.333 & 11 \\
\hline $\begin{array}{l}\text { Patti Pics Near Vision Eye } \\
\text { Test Chart }\end{array}$ & 0.319 & 12 & 0.324 & 12 \\
\hline Tumbling E chart & 0.331 & 11 & 0.323 & 13 \\
\hline $\begin{array}{l}\text { Instrumental Activities of Daily } \\
\text { Living Scale }{ }^{43}\end{array}$ & 0.045 & 14 & 0.043 & 14 \\
\hline Feinbloom distance chart & -0.023 & 15 & -0.008 & 15 \\
\hline $\begin{array}{l}\text { City University Colour Vision } \\
\text { Test }\end{array}$ & -0.072 & 17 & -0.106 & 16 \\
\hline Ishihara plates ${ }^{44}$ & 0.076 & 16 & -0.131 & 17 \\
\hline Pupil reflex & -0.451 & 18 & -0.469 & 18 \\
\hline $\begin{array}{l}\text { Neuro-ophthalmic } \\
\text { assessment }\end{array}$ & -0.772 & 19 & -0.812 & 19 \\
\hline Peek app ${ }^{45}$ & -1.618 & 21 & -1.385 & 20 \\
\hline Autorefractor & -1.406 & 20 & -1.462 & 21 \\
\hline Fundus photography ${ }^{46}$ & -1.903 & 22 & -1.981 & 22 \\
\hline
\end{tabular}

the top four hearing screening tests were the Hearing Handicap Inventory for the Elderly, the Whisper Test, the Measure of Severity of Hearing Loss, and the Hyperacusis Questionnaire, respectively. The panel, however, reserved the right to revisit the final choice for the measures to be included in the sensory screening toolkit evaluation, because the use of some of the suggested questionnaires in the context of hearing screening would likely underestimate true cases of hearing impairment, and is seriously limited in cases where verbal communication is impaired due to more severe cognitive decline. In addition, the panel members suggested to potentially include otoscopy even though it was not scored in the top five, because the hearing specialists on the panel argued strongly for testing the feasibility of examining the anatomy of the ear by nurses, as it is impossible to complete an assessment of hearing if the external canal is obstructed with cerumen. ${ }^{33}$ In addition, the
Finger Rub Test was suggested, even though it had been excluded at the literature review level, given the absence of a validated administration and comparison standard; however, the panel proposed its inclusion given its simplicity of administration and recent reports on its high sensitivity when administered to older adults. ${ }^{34}$

\section{DISCUSSION}

The goal of the present study was to come to a consensus among specialists in sensory and cognitive ageing on which tools and techniques may be the most suitable for nurses when screening for vision and hearing impairments in older adults with dementia living in LTCHs. Our two-stage consensus approach was based on previously presented tests of vision ${ }^{22}$ and hearing (W. Wittich et al., in preparation) that could potentially be used with older adults who have cognitive impairment, as well as qualitative insights from sensory specialists ${ }^{25}$ and nurses working in LTCHs. ${ }^{16}$ Interestingly, the most highly ranked vision screening tests relied on observable visual behaviours, such as responding to the visibility of stimuli and actions within the central or peripheral visual field. In contrast, three of the top four hearing screening tests were questionnaires to be verbally administered to either the patient (in cases where they were able to comprehend and respond to the items) or individuals in their environment (eg, care providers or family members). Only the Whisper Test, as a measure of observable auditory response behaviour, was ranked sufficiently high to be deemed suitable. Consequently, the Finger Rub Test was added to this list at the discussion level of round 3 .

The qualitative comments of the consensus panel members, specifically on the evaluation forms of round 1 and in the discussions during round 3 , highlighted that the majority of tests and tools were ranked low or considered limited in usefulness due to their incompatibility with the scope and practicality of care provision by nurses in LTCHs. For example, tools that have to be specifically purchased, tools that are not easily portable, or that require extra space or time for administration and calibration are unlikely to be accepted and integrated into the work routine of nurses whose time and resources are already strained. These limitations would explain why the top-ranked vision tests do not require equipment (eg, confrontation fields, counting fingers and hand motion), or can easily fit into a pocket (the modified Lighthouse test is available in the shape of a bookmark), and the top-ranked hearing tests are verbally administered questionnaires (even though scoring and keeping a record of the responses would require pen and paper) or do not require equipment (Whisper Test, Finger Rub Test). Such simplicity of testing and readiness of use would allow for easy implementation and more likely adoption into the clinical environment. This desired and/or required simplicity stands in opposition to many of the tools used in research that require 
Table 5 The $z$-scores for hearing tests with final rankings at rounds 1 and 2

\begin{tabular}{|c|c|c|c|c|}
\hline \multirow[b]{2}{*}{ Tool } & \multicolumn{4}{|c|}{ Mean z-scores and rankings } \\
\hline & Round 1 & Rank & Round 2 & Rank \\
\hline Hearing Handicap Inventory for the Elderly ${ }^{23}$ & 0.647 & 1 & 0.647 & 1 \\
\hline $\begin{array}{l}\text { Measure of severity of hearing loss (hearing item of the interRAI Community Health } \\
\text { Assessment }{ }^{49} \text { ) }\end{array}$ & 0.528 & 3 & 0.528 & 3 \\
\hline Case history & 0.481 & 5 & 0.481 & 6 \\
\hline Nursing Home Hearing Handicap Index for Carer ${ }^{24}$ & 0.479 & 6 & 0.479 & 7 \\
\hline Tinnitus Handicap Inventory ${ }^{51}$ & 0.439 & 7 & 0.439 & 8 \\
\hline Nursing Home Hearing Handicap Index for Patient ${ }^{24}$ & 0.433 & 8 & 0.433 & 9 \\
\hline Minimum Data Set (V.2.0) Functional Hearing Impairment Questionnaire ${ }^{54}$ & 0.329 & 13 & 0.329 & 13 \\
\hline InterRAI Long-Term Care Facilities ${ }^{55}$ & 0.088 & 14 & 0.088 & 14 \\
\hline InterRAI Acute Care ${ }^{56}$ & -0.260 & 15 & -0.260 & 15 \\
\hline Adolescent/Adult sensory profile & -0.759 & 16 & -0.759 & 16 \\
\hline Otoscopy & -1.058 & 17 & -1.058 & 17 \\
\hline Pure tone audiometry & -1.244 & 18 & -1.224 & 18 \\
\hline Otoacoustic emissions test & -1.912 & 19 & -1.707 & 19 \\
\hline Cerumen removal & -2.258 & 20 & -2.258 & 20 \\
\hline
\end{tabular}

controlled conditions (eg, luminance calibration or measurements of background noise), which are not possible in a constantly changing testing environment.

Another prominent topic that emerged during the evaluation process by the panel members was the difficulty in judging suitability across the severity levels of cognitive impairment. The panellists agreed that questionnaires, for example, could easily be a measure of choice for LTCH residents without hearing loss, those with mild cognitive impairment or those whose cognitive abilities still allow them to interact verbally in a meaningful way. However, in residents at more advanced stages of dementia, or those with more severe hearing loss, verbal engagement may not be reliable or attainable, making questionnaires unsuitable. Similarly, responding to the task of naming letter optotypes on a vision test, such as the HOT-V chart, may pose problems to some residents with advanced cognitive decline. Even though they may still be able to resolve the targets at the ocular level, they may not be able to process this information at the cortical level or link the stimulus to its meaning, and be able to verbally express it. Such difficulties have been described in cases of posterior cortical atrophy, where the visual cortex is affected earlier than other processing areas. ${ }^{35} 36$ The topic of the cognitive spectrum had also previously been raised during our consultation with nurses working in the LTCH setting, ${ }^{16}$ as well as with sensory specialists, ${ }^{25}$ whose proposed recommendations focused on the use of familiar and personalised stimuli that are meaningful to the resident. For example, members of the panel suggested that speaking the individual's name to observe whether they would orient towards the speaker, and similarly writing their name or presenting a photograph of a family member, and observing whether the individual orients towards the photo or shows a facial response when viewing the image, might be a more suitable screening approach. Such stimuli may not be standardised, but would still give the nurse a better idea as to the sensory (and cognitive) status of their patient, especially when behavioural responses can only be elicited in this way.

The panel member whose specialty was rehabilitation service delivery for individuals with combined vision and hearing impairment brought a unique and important perspective to the ranking and panel discussion process, which in part explained some of the scoring outliers. Specifically, this individual raised concerns about the feasibility of testing vision in the presence of coexisting hearing loss and vice versa, given that the majority of older adults with combined vision and hearing loss are affected with late-onset sensory impairments, such as age-related macular degeneration and presbycusis, ${ }^{37}$ a multimorbidity that is highly prevalent in LTCHs, ${ }^{38}$ especially in those with cognitive 
impairments. ${ }^{14}$ For many vision tests, the screening for vision impairment is further complicated by the need to rely on hearing to administer the instructions of the test; therefore, sensory screening in the presence of sensory and cognitive multimorbidity is a challenge that remains to be explored and addressed by future research. Early attempts at developing suitable tactile assessment measures are currently ongoing ${ }^{39}$ and will likely continue to be refined as the need for such evaluations increases.

Given the complexity of both the study topic and the realities of the LTCH environment, there are various limitations that need to be considered when interpreting our findings. First, use of a combined quantitative and qualitative consensus method itself may be limited in its ability to give rise to the optimal recommendations for sensory screening tools, because its reactive nature may limit the influence of clinical intuition of some panel members. Even though we are confident in the abilities of our panellists and their ability to provide qualitative feedback during the consensus process, it is possible that a different group of specialists or a more diverse geographical or specialty representation may have resulted in different rankings of the presented tools. The panel members were asked to view the measures with the administrative realities of nurses working in LTCHs in mind. However, only some of the clinician panellists had previously provided vision and/or hearing health services inside such an environment themselves (possibly hinting at the lack of such care provision in LTCHs, even though their rankings were quite similar for the majority of the measures). In addition, this exercise in perspective-taking, where a researcher views the problem through the eyes of a clinician, may not be the perfect approach to the scoring of tests. Previous work using this approach has demonstrated priority differences between clinical and research goals when using perspective-taking. ${ }^{40}$ This effect may also be reflected in our acceptable, but not excellent, intercoder agreement values of Krippendorff's alpha. We hope to balance out such possible differences by presenting our findings in the context of consultation with nurses working in LTCHs at an earlier phase of this project. ${ }^{16}$ The next step focuses on resolving these concerns by developing and validating a sensory screening toolkit in collaboration with LTCH nurses. In this final phase, we will be using the recommended vision and hearing tests presented here, with nurses administering these tests in the LTCH environment, to judge their feasibility, and test their reliability and validity, by comparing this screening with the complete sensory examinations of LTCH residents by vision and hearing specialists. This final phase is currently ongoing.

The present study highlights the need for a better understanding of the links between sensory and cognitive abilities in older adults, both from a research and a clinical perspective. Particularly in the context of care and assessment of older adults living in LTCH, who require complex care due to multimorbidity, including sensory and cognitive abilities, we are currently ill-equipped to truly grasp their needs and capacities. The present study forms an additional step towards the development and validation of a sensory toolkit specifically designed to assist nurses working in LTCHs in identifying residents with dementia that could benefit from sensory interventions. Once the feasibility of this toolkit has been evaluated and its use validated, the ultimate goal is to implement such sensory screening methods more widely throughout LTCHs, in order to bring appropriate vision and hearing care to all residents who can benefit from it, specifically those who may be unable to advocate for and express such needs themselves.

\section{Author affiliations}

${ }^{1}$ School of Optometry, Université de Montréal, Montreal, Quebec, Canada ${ }^{2}$ Centre de recherche interdisciplinaire en réadaptation du Montréal métropolitain, Montreal, Quebec, Canada

${ }^{3}$ Toronto Rehabilitation Institute, University Health Network, Toronto, Ontario, Canada ${ }^{4}$ Rehabilitation Sciences Institute, University of Toronto, Toronto, Ontario, Canada ${ }^{5}$ Lawrence S. Bloomberg Faculty of Nursing, University of Toronto, Toronto, Ontario, Canada

\section{Twitter@WalterWittich}

Acknowledgements We would like to thank Aaron Johnson and Christine Lehane for their guidance with some of the analyses.

Contributors KSM is responsible for project conception, and along with $\mathrm{FH}$ and WW for writing the protocol. FH, KSM and WW obtained ethics approval. JJ and WW collected the data and conducted the data analysis. WW, FH, JJ and KSM were involved in data interpretation, and in writing, editing and revising the manuscript.

Funding This work was supported by the Alzheimer Society Research Program (ASRP), Alzheimer Society of Canada (grant number RG 16-08). WW is supported by an FRQ-S Junior 1 career award (nos 28881 and 30620). Dr. McGilton is supported by the Walter and Maria Schroeder Institute for Brain Innovation \& Recovery.

Competing interests None declared.

Patient consent for publication Not required.

Ethics approval The overall protocol received ethics approval from the Research Ethics Boards of the University Health Network, Toronto, Canada (REB\#159663-DE), and adhered to the tenets of the Declaration of Helsinki for research with human participants. The consensus process itself took place between January and April 2017.

Provenance and peer review Not commissioned; externally peer reviewed.

Data availability statement Data are available upon reasonable request.

Open access This is an open access article distributed in accordance with the Creative Commons Attribution Non Commercial (CC BY-NC 4.0) license, which permits others to distribute, remix, adapt, build upon this work non-commercially, and license their derivative works on different terms, provided the original work is properly cited, appropriate credit is given, any changes made indicated, and the use is non-commercial. See: http://creativecommons.org/licenses/by-nc/4.0/.

\section{REFERENCES}

1. Schubert CR, Cruickshanks KJ, Fischer ME, et al. Sensory impairments and cognitive function in middle-aged adults. Journals Gerontol Ser A 2017;00:1-4.

2. Albers MW, Gilmore GC, Kaye J, et al. At the interface of sensory and motor dysfunctions and Alzheimer's disease. Alzheimer's \& Dementia 2015;11:70-98.

3. Panza F, Solfrizzi V, Seripa D, et al. Age-Related hearing impairment and frailty in Alzheimer's disease: interconnected associations and mechanisms. Front Aging Neurosci 2015;7. 
4. Lang P-O, Michel J-P, Zekry D. Frailty syndrome: a transitional state in a dynamic process. Gerontology 2009;55:539-49.

5. Lindenberger $\mathrm{U}$, Scherer $\mathrm{H}$, Baltes $\mathrm{PB}$. The strong connection between sensory and cognitive performance in old age: not due to sensory acuity reductions operating during cognitive assessment. Psychol Aging 2001;16:196-205.

6. Lindenberger $U$, Baltes $P B$. Sensory functioning and intelligence in old age: a strong connection. Psychol Aging 1994;9:339-55.

7. Wettstein M, Wahl H, Heyl V. Visual Acuity and Cognition in Older Adults With and Without Hearing Loss : Evidence For Late-Life Sensory Compensation ? Ear Hear 2018;39:746-55.

8. Wahl H, Heyl V. Connections between vision, hearing, and cognitive function in old age. Generations 2003;27:39-45.

9. Wayne RV, Johnsrude IS. A review of causal mechanisms underlying the link between age-related hearing loss and cognitive decline. Ageing Res Rev 2015;23:154-66.

10. Salthouse TA, Hancock HE, Meinz EJ, et al. Interrelations of age, visual acuity, and cognitive functioning. The Journals of Gerontology Series B: Psychological Sciences and Social Sciences 1996;51B:P317-30.

11. Chriqui E, Law C, Kergoat M-J, et al. Visual impairment in older institutionalised Canadian seniors with dementia. Ophthalmic Physiol Opt 2017:37:225-33

12. Guthrie DM, Davidson JGS, Williams N, et al. Combined impairments in vision, hearing and cognition are associated with greater levels of functional and communication difficulties than cognitive impairment alone: analysis of interRAI data for home care and long-term care recipients in Ontario. PLoS One 2018;13:e0192971.

13. Seitz D, Purandare N, Conn D. Prevalence of psychiatric disorders among older adults in long-term care homes: a systematic review. Int Psychogeriatr 2010;22:1025-39.

14. Mitoku K, Masaki N, Ogata Y, et al. Vision and hearing impairments, cognitive impairment and mortality among long-term care recipients: a population-based cohort study. BMC Geriatr 2016;16:112.

15. Slaughter SE, Hopper T, Ickert C, et al. Identification of hearing loss among residents with dementia: perceptions of health care aides. Geriatr Nurs 2014;35:434-40.

16. Höbler F, Argueta-Warden X, Rodríguez-Monforte M, et al. Exploring the sensory screening experiences of nurses working in long-term care homes with residents who have dementia: a qualitative study. BMC Geriatr 2018;18:235

17. McDonnall MC, Crudden A, LeJeune BJ, et al. Needs and challenges of seniors with combined hearing and vision loss. J Vis Impair Blind 2016;110:399-411.

18. Dupuis K, Marchuk V, Pichora-Fuller MK. Noise affects performance on the Montreal cognitive assessment. Can J Aging 2016;35:298-307.

19. Bertone A, Wittich W, Watanabe $\mathrm{D}$, et al. The effect of age-related macular degeneration on non-verbal neuropsychological test performance. International Congress Series 2005;1282:26-30.

20. Dawes P, Pye A, Reeves D, et al. Protocol for the development of versions of the Montreal cognitive assessment (MoCA) for people with hearing or vision impairment. BMJ Open 2019;9:e026246.

21. McGilton KS, Höbler F, Campos J, et al. Hearing and vision screening tools for long-term care residents with dementia: protocol for a scoping review. BMJ Open 2016:6:e011945.

22. Campos JL, Höbler F, Bitton E, et al. Screening for vision impairments in individuals with dementia living in long-term care: a scoping review. J Alzheimers Dis 2019;68:1039-49.

23. Ventry IM, Weinstein BE. The hearing handicap inventory for the elderly. Ear Hear 1982;3:128-34.

24. Schow R, Nerbonne M. Assessment of hearing handicap by nursing home residents and staff. J Acad Rehabil Audiol 1977;10:2-12.

25. Wittich W, Höbler F, Jarry J, et al. Recommendations for successful sensory screening in older adults with dementia in long-term care: a qualitative environmental scan of Canadian specialists. BMJ Open 2018:8:e019451.

26. Demers L, Weiss-Lambrou R, Ska B. Development of the Quebec user evaluation of satisfaction with assistive technology (quest). Assistive Technology 1996;8:3-13.

27. Fish LS, Busby DM. The Delphi method. Res Methods Fam Ther 2005:238-53.

28. McKenna HP. The Delphi technique: a worthwhile research approach for nursing? J Adv Nurs 1994;19:1221-5.

29. Ritchie C, Jones E. Consulting the oracle? Int J Contemp Hospitality Mngt 2012;24:886-906.
30. Powell C. The Delphi technique: myths and realities. J Adv Nurs 2003;41:376-82.

31. Forscher P, Cox W, Devine P, et al. How many reviewers are required to obtain reliable evaluations of $\mathrm{NIH}$ R01 grant proposals? Preprint 2019 https://psyarxiv.com/483zj (accessed 11 Apr 2019).

32. Hayes AF, Krippendorff K. Answering the call for a standard reliability measure for coding data. Commun Methods Meas 2007;1:77-89.

33. Fook L, Morgan R. Hearing impairment in older people: a review. Postgrad Med J 2000;76:537-41.

34. Strawbridge WJ, Wallhagen MI. Simple tests compare well with a hand-held Audiometer for hearing loss screening in primary care. $J$ Am Geriatr Soc (Published Online First: 11 August 2017).

35. Freedman L, Selchen DH, Black SE, et al. Posterior cortical dementia with alexia: neurobehavioural, MRI, and PET findings. Journal of Neurology, Neurosurgery \& Psychiatry 1991;54:443-8.

36. Yong KXX, Rajdev K, Shakespeare TJ, et al. Facilitating text reading in posterior cortical atrophy. Neurology 2015;85:339-48.

37. Wittich W, Watanabe DH, Gagné J-P. Sensory and demographic characteristics of deafblindness rehabilitation clients in Montréal, Canada. Ophthalmic Physiol Opt 2012;32:242-51.

38. Yamada Y, Onder G, Denkinger MD, et al. P235: prevalence and correlates of dual sensory impairment in nursing homes: results from the shelter study. Eur Geriatr Med 2014;5:S158.

39. Bruhn P, Dammeyer J. Assessment of dementia in individuals with dual sensory loss: application of a tactile test battery. Dement Geriatr Cogn Dis Extra 2018:8:12-22.

40. Bergman AA, Delevan DM, Miake-Lye IM, et al. Partnering to improve care: the case of the Veterans' Health Administration's Quality Enhancement Research Initiative. J Health Serv Res Policy 2017;22:139-48.

41. Anstice NS, Jacobs RJ, Simkin SK, et al. Do picture-based charts overestimate visual acuity? comparison of Kay pictures, Lea symbols, HOTV and Keeler logMAR charts with Sloan letters in adults and children. PLoS One 2017:12:e0170839-17.

42. Snellen H. Probebuchstaben Zur bestimmung Der sehschärfe. Utrecht, Van der Weijer, 1892

43. Lawton MP, Brody EM. Assessment of older people: selfmaintaining and instrumental activities of daily living. Gerontologist 1969;9:179-86.

44. Ishihara S. Tests for Color-Blindness. Nature 1972;24.

45. Bastawrous A, Rono HK, Livingstone IAT, et al. Development and validation of a smartphone-based visual acuity test (peek acuity) for clinical practice and community-based fieldwork. JAMA Ophthalmol 2015;133:930-7.

46. Thorno W. Die stereoskopische Photographie des Augenhintergrundes. Klin Monbl Augenheilkd 1909;47.

47. Swan IR, Browning GG. The whispered voice as a screening test for hearing impairment. J R Coll Gen Pract 1985;35:197.

48. MacPhee GJA, CROWTHER JA, MCALPINE CH. A simple screening test for hearing impairment in elderly patients. Age Ageing 1988; $17: 347-51$

49. Morris J, Berg K, Bjorkgren M, et al. interRAl community health ( $\mathrm{CHA})$ assessment form and user's manual. Version 9.1 (Canadian Edition edition). Washington, D.C 2010.

50. Khalfa S, Dubal S, Veuillet E, et al. Psychometric normalization of a hyperacusis questionnaire. ORL 2002;64:436-42.

51. Newman CW, Jacobson GP, Spitzer JB. Development of the tinnitus handicap inventory. Arch Otolaryngol Head Neck Surg 1996;122:143-8.

52. Davis AC. The prevalence of hearing impairment and reported hearing disability among adults in Great Britain. Int J Epidemiol 1989;18:911-7.

53. Ouchi Y, Meguro K, Akanuma K, et al. Normal Hearing Ability but Impaired Auditory Selective Attention Associated with Prediction of Response to Donepezil in Patients with Alzheimer's Disease. Behav Neurol 2015;2015:1-6.

54. Abicht-Swensen LM, Debner LK. The minimum data set 2.0: a functional assessment to predict mortality in nursing home residents. Am J Hosp Palliat Care 1999;16:527-32.

55. Morris J. interRAI Long-Term Care Facilities (LTF) Assessment Form and User's Manual. 9.1. interRAI Publ 2010.

56. Gray L, Arino-Blasco S, Fries BE, et al. interRAI Acute Care for Comprehensive Geriatric Assessment (AC-CGA) form and user's manual. Version 9.32017. 